\title{
High incidence of disease recurrence after discontinuation of disease-modifying antirheumatic drug treatment in patients with psoriatic arthritis in remission
}

\author{
Elizabeth G Araujo, ${ }^{1}$ Stephanie Finzel, ${ }^{1}$ Matthias Englbrecht, ${ }^{1}$ Dominik A Schreiber, ${ }^{1}$ \\ Francesca Faustini, ${ }^{1}$ Axel Hueber, ${ }^{1}$ Kemal Nas, ${ }^{1,2}$ Juergen Rech, ${ }^{1}$ Georg Schett ${ }^{1}$
}

\section{Handling editor Tore K Kvien \\ ${ }^{1}$ Department of Internal Medicine 3 and Institute for Clinical Immunology, University of Erlangen-Nuremberg, Erlangen, Germany \\ ${ }^{2}$ Department of Physical Medicine and Rehabilitation, University of Dicle, Diyarbakir, Turkey}

\section{Correspondence to} Professor Georg Schett, Department of Internal Medicine 3 and Institute for Clinical Immunology, University of Erlangen-Nuremberg, Ulmenweg 18, Erlangen 91054, Germany; georg.schett@uk-erlangen.de

Received 4 July 2013 Revised 20 September 2013 Accepted 24 November 2013 Published Online First 12 December 2013
CrossMark

To cite: Araujo EG, Finzel $S$, Englbrecht $\mathrm{M}$, et al. Ann Rheum Dis 2015;74: 655-660.

\section{ABSTRACT}

Objective To investigate the possibility of drug-free remission in patients with psoriatic arthritis (PsA) in continuous remission.

Methods Prospective observational study in diseasemodifying antirheumatic drug (DMARD)-treated PsA patients in continuous disease remission (no musculoskeletal symptoms, no or minimal skin/nail disease) for at least 6 months. Demographic, diseasespecific and ultrasound parameters were assessed at baseline. DMARDs (traditional or biologic) were discontinued at the initial visit, and patients were followed for a maximum of 6 months for recurrence of disease.

Results 26 patients (methotrexate monotherapy: $\mathrm{N}=14$; tumour necrosis factor inhibitors: $\mathrm{N}=12$ ) with a mean age of 55.2 years, absence of musculoskeletal symptoms and minimal skin disease (mean Psoriasis Area Severity Index (PASI): 0.21) were enrolled. Incidence of recurrence of disease was high $(\mathrm{N}=20$, $76.9 \%)$ and occurred rapidly (74.50 \pm 51.72 days) after treatment discontinuation. Male PsA patients were significantly more likely to lose remission. Long disease duration, more severe skin involvement and the presence of synovial hypertrophy by ultrasonographic examination at baseline decreased the likelihood for drug-free remission. Reinitiation of DMARDs promptly restored remission in all PSA patients with recurrence of disease. Conclusions This study shows that the chance to reach drug-free remission in PsA patients is low. Discontinuation of DMARD therapy cannot be recommended in patients with PsA.

\section{INTRODUCTION}

Psoriatic arthritis (PsA) is a chronic inflammatory disease with a wide spectrum of clinical manifestations. For a long time, PsA was thought to be a more benign disease in comparison to rheumatoid arthritis. ${ }^{1}$ In some cases, PsA can indeed manifest as a rather mild disease, allowing disease management with non-steroidal anti-inflammatory drugs. However, most of the patients developing PsA experience a chronic disease course with joint pain and swelling, but also symptoms arising from enthesitis and dactylitis, which, if not treated appropriately, leads to the destruction of the periarticular cartilage and bone, as well as to enthesophyte formation, which impairs function. ${ }^{2}$ These patients profit from the timely start and continuous maintenance of immunomodulatory drug therapy. ${ }^{3-5}$ Some of the most common diseasemodifying antirheumatic drugs (DMARDs) currently used for the management of PsA include methotrexate and tumour necrosis factor inhibitors (TNFi). ${ }^{6}{ }^{7}$ Whereas TNFi has consistently shown efficacy in improving the signs and symptoms of PsA and limited data also suggest retardation of structural progression, the effect of methotrexate in PsA is more controversial. ${ }^{8}{ }^{9}$ Nonetheless, methotrexate is widely used as a first-line DMARD treatment in patients with PsA-a treatment strategy that has been borrowed from the treatment of rheumatoid arthritis.

Improved diagnosis of PsA associated with earlier initiation of DMARD therapy, better monitoring strategy of the disease and the use of TNFi have improved the management of PsA patients. Formal criteria for remission of PsA have so far not been defined. ${ }^{10-16}$ Attributing to the higher likelihood of robust control of signs and symptoms in PsA by modern therapy, a state of minimal disease activity in PsA has been defined recently. ${ }^{17}$ This can be used as a target of treatment in patients with PsA. The state of minimal disease activity is based on measures of joint disease, skin disease, entheseal involvement and the functional state of the patient.

Ideally, effective antirheumatic treatment of patients with PsA reaches a state characterised by the virtual absence of musculoskeletal symptoms and signs of psoriatic skin disease.

If persistent, such disease state raises the question whether further treatment with DMARD may cause more harm or benefit. Furthermore, patients challenge doctors with the question of whether to stop therapy for treatment of PsA when the disease is in stable remission.

We, therefore, searched for patients with PsA who showed complete control of symptoms related to joints, skin and entheseal disease, and who also did not show any impairment in their functional status or quality of life. We investigated whether discontinuation of DMARD treatment is a feasible option in these patients and tested whether remission is sustained after DMARD treatment has been stopped. 


\section{METHODS}

\section{Patients and study design}

This was a prospective single-centre observational study conducted at the Department of Internal Medicine 3 of the University of Erlangen-Nuremberg, Germany. Patients were recruited from January 2011 to July 2012. The following inclusion criteria were applied: (i) diagnosis of PsA according to the CASPAR criteria; (ii) documented absence of clinical symptoms related to arthritis, dactylitis, enthesitis and axial disease for at least 6 months; (iii) minimal skin disease with a Psoriasis Area Severity Index (PASI) of less than 1; and (iv) continuous and stable treatment with conventional or biological DMARDs for the last 6 months. Disease-modifying antirheumatic therapy (DMARDs, TNFi) was discontinued without any tapering of the dose at study entry, and patients were followed for 6 months with clinical examination at baseline, 3 and 6 months after cessation of medication. The use of non-steroidal anti-inflammatory drug was allowed during the study. Patients completed the study when experiencing recurrence of disease or when reaching 6 months of drug-free remission. All patients signed an informed consent agreeing to participate in the study.

\section{Baseline clinical assessments}

Demographic characteristics, including age, gender, height, weight and body mass index, were assessed at baseline. Disease duration of psoriatic skin disease and duration of PsA were documented as well as the duration of remission. Type and duration of antirheumatic drug therapy, including the use of methotrexate, TNFi and glucocorticoids, were recorded.
Musculoskeletal disease activity was assessed by Tender Joint Count (TJC 68), Swollen Joint Count (SJC 66) and three 0$10 \mathrm{~cm}$ visual analogue scales with respect to pain (VAS patient pain), patient global perception of disease activity (VAS patient global) and the physician's global evaluation of disease activity (VAS physician global).

Function was assessed by the Health Assessment Questionnaire-Disability Index (HAQ-DI), quality of life by the Medical Outcomes Study Short Form-36 (SF-36) and fatigue by the Functional Assessment of Chronic Illness Therapy Fatigue questionnaire (FACIT-F). For documentation of musculoskeletal disease activity, the following scores were calculated: the Disease Activity Score (DAS28 CRP), the Maastricht Ankylosing Spondylitis Enthesitis Score (MASES), the Leeds Dactylitis Index (LDI) and the Bath Ankylosing Spondylitis Disease Activity Index (BASDAI). Psoriatic skin and nail disease activity were measured by the PASI and the Nail Psoriasis Severity Index (NAPSI), respectively. In addition, two PsA composite scores were calculated: the Disease Activity Index for Psoriatic Arthritis (DAPSA) and the Psoriatic Arthritis Disease Activity Score (PASDAS). Erythrocyte sedimentation rate (ESR) and the level of C-reactive protein were measured to assess acute-phase response.

\section{Baseline ultrasound examination}

Ultrasound examination of 30 joints and 20 entheses was performed at baseline. The following joints were assessed: both wrists, right and left metacarpophalangeal joints 2-5, right and left proximal interphalangeal joints $2-5$, both knees, and right

Table 1 Patient's characteristics at baseline

\begin{tabular}{|c|c|c|c|c|c|c|c|c|}
\hline & $\mathrm{N}$ & Min & Max & Mean & SD & $95 \% \mathrm{Cl}$ of mean & Median & IQR \\
\hline Age (years) & 26 & 23 & 85 & 55.23 & 14.48 & (49.38 to 61.08$)$ & 53 & 21 \\
\hline Body mass index & 26 & 21.6 & 38.3 & 26.50 & 3.67 & (25.02 to 27.98 ) & 26.25 & 4.2 \\
\hline Duration of PsA (years) & 26 & 1 & 26 & 6.54 & 6.72 & (3.82 to 9.25$)$ & 4 & 4 \\
\hline Duration of remission (months) & 26 & 6 & 120 & 23.92 & 23.68 & (14.36 to 33.49$)$ & 16.50 & 25 \\
\hline Duration of DMARD (months) & 21 & 7 & 60 & 34.38 & 13.89 & (28.06 to 40.70 ) & 36 & 22 \\
\hline Duration of TNFi (months) & 12 & 7 & 145 & 41.17 & 35.97 & (18.31 to 64.02$)$ & 35 & 30 \\
\hline TJC 68 & 26 & 0 & 2 & 0.19 & 0.56 & $(-0.04$ to 0.42$)$ & 0 & 0 \\
\hline SJC 66 & 26 & 0 & 0 & 0 & 0 & $(0$ to 0$)$ & 0 & 0 \\
\hline VAS patient global $(\mathrm{cm})$ & 24 & 0 & 3 & 0.83 & 0.93 & (0.44 to 1.22 ) & 0.55 & 1.50 \\
\hline VAS patient pain $(\mathrm{cm})$ & 22 & 0 & 2 & 0.67 & 0.77 & (0.33 to 1.01$)$ & 0.35 & 1 \\
\hline VAS physician global (cm) & 25 & 0 & 1 & 0.10 & 0.22 & (0.01 to 0.19$)$ & 0 & 0 \\
\hline CRP (mg/L) & 26 & 0.2 & 8.1 & 1.76 & 2.05 & (0.93 to 2.59 ) & 1.05 & 1.40 \\
\hline $\mathrm{ESR}(\mathrm{mm} / \mathrm{h})$ & 22 & 1 & 36 & 8.64 & 7.71 & (5.22 to 12.06 ) & 8 & 8 \\
\hline DAS-28 CRP & 25 & 0.96 & 2.34 & 1.37 & 0.36 & (1.22 to 1.52$)$ & 1.28 & 0.60 \\
\hline DAPSA & 22 & 0.03 & 6.03 & 1.85 & 1.64 & (1.13 to 2.58 ) & 1.95 & 2.64 \\
\hline PASDAS & 23 & 0.20 & 3.41 & 1.12 & 0.78 & (0.78 to 1.46$)$ & 1.08 & 1.27 \\
\hline HAQ-DI & 26 & 0 & 2.12 & 0.16 & 0.44 & $(-0.02$ to 0.33$)$ & 0 & 0.12 \\
\hline SF-36 (physical component scale) & 24 & 20.91 & 62.75 & 50.6 & 9 & (46.80 to 54.39 ) & 53.45 & 7.29 \\
\hline SF-36 (mental component scale) & 24 & 33.46 & 62.16 & 52.9 & 6.37 & (50.20 to 55.59$)$ & 54.26 & 8.54 \\
\hline FACIT-F & 22 & 27 & 52 & 45 & 6.73 & (42.02 to 47.98 ) & 47 & 8 \\
\hline MASES & 26 & 0 & 0 & 0 & 0 & $(0$ to 0$)$ & 0 & 0 \\
\hline LDI & 26 & 0 & 0 & 0 & 0 & $(0$ to 0$)$ & 0 & 0 \\
\hline BASDAI & 23 & 0 & 3.6 & 1.55 & 1.16 & (1.04 to 2.05$)$ & 1.60 & 2.10 \\
\hline PASI & 26 & 0 & 2.4 & 0.21 & 0.56 & (-0.01 to 0.44$)$ & 0 & 0 \\
\hline NAPSI & 26 & 0 & 26 & 4.30 & 6.90 & (1.52 to 7.09 ) & 2 & 5 \\
\hline
\end{tabular}

SJC, MASES, LDI: no descriptive statistics were calculated due to values of all patients being 0 .

BASDAl, Bath Ankylosing Spondylitis Disease Activity Index; DAPSA, Disease Activity index for Psoriatic Arthritis; DMARD, disease-modifying antirheumatic drug; ESR, erythrocyte sedimentation rate; LDI, Leeds Dactylitis Index; MASES, Maastricht Ankylosing Spondylitis Enthesitis Score; NAPSI, Nail Psoriasis Severity Index; PASDAS, Psoriatic Arthritis Disease Activity Score; PASI, Psoriasis Area Severity Index; SJC, Swollen Joint Count; TJC, Tender Joint Count; VAS, visual analogue scale. 
and left metatarsophalangeal joints 1-5. Each joint was evaluated for the presence of synovial hypertrophy, joint effusion and the presence of power Doppler signal. Regarding the entheses, the following sites were examined bilaterally: common extensor tendons of the forearm, triceps tendon, extensor carpi ulnar tendon, tibialis anterior, peroneus brevis, plantar fascia, Achilles tendon, quadriceps femoris tendon, patellar ligament superior and patellar ligament inferior. Each entheseal site was evaluated for the presence or absence of enthesophytes, calcifications, erosions, bursitis and vascularisation. The ultrasound examination was performed by an independent investigator skilled in musculoskeletal ultrasound (SF), who was not involved in patient recruitment and follow-up.

\section{Documentation of flares}

All patients were instructed to call the treating physician's office in case of increasing symptoms. Symptoms were then documented based on a phone interview, and patients were scheduled to be seen in the office within 7 days. If a flare was documented by the physician, therapy was restarted immediately. Data regarding duration of drug-free interval until recurrence of symptoms were documented. The presence of arthritis, as defined by at least one swollen joint, as well as the presence of dactylitis, enthesitis and inflammatory back pain, was documented. Psoriatic skin disease activity was measured by the PASI. Pain VAS (VAS patient pain), patient global VAS (VAS patient global) and physician's global VAS (VAS physician global) were also obtained at the time of recurrence of disease.

\section{Statistical analysis}

Descriptive statistics was used to outline demographic and clinical features for the total sample, as well as for stratified subgroups of patients experiencing a flare and those who did not. Descriptive data include sample size, arithmetic means \pm SDs, minimum as well as maximum values and 95\% CIs of means. Missing values were not imputed to preserve the original information of the data. Inferential testing of potential differences between patients that flared and those that remained in remission was done by $\chi^{2}$ test for categorical data and MannWhitney $U$ test or independent samples $t$ test for parametric data, depending on whether the assumption of Gaussian distribution of sample means was met. The tests were supposed to investigate the differences between the aforementioned subgroups with respect to demographics and disease activity parameters. All statistical analyses were computed using IBM SPSS Statistics V.19 software.

\section{RESULTS}

\section{Patient's characteristics}

In total, 26 PsA patients (20 male, 6 female) in continuous disease remission for at least 6 months were enrolled. Of the 26 patients, $15(57.69 \%)$ had polyarthritis, $6(23.07 \%)$ had oligoarthritis, 4 (15.38\%) had axial disease and 1 (3.84\%) had distal interphalangeal joint disease. Demographic characteristics and disease activity measurements at baseline are summarised in table 1. Mean $( \pm S D)$ age was $55.23( \pm 14.48)$ years and mean $( \pm \mathrm{SD})$ duration of PsA was $6.54( \pm 6.72)$ years. Patients experienced disease remission for a mean $( \pm S D)$ of $23.92( \pm 23.68)$ months, with a median of 16.5 months (range 6-120 months). Regarding antirheumatic therapy, the majority of patients were treated with methotrexate $(\mathrm{N}=14,53.8 \%)$. Biological therapy with TNFi was being used in 12 patients (46.2\%), either as monotherapy $(\mathrm{N}=5,19.2 \%)$ or in combination with methotrexate $(\mathrm{N}=7,26.9 \%)$. Mean duration $( \pm \mathrm{SD})$ of DMARD therapy

\begin{tabular}{|c|c|c|c|c|c|c|}
\hline & $\mathrm{N}$ & Min & Max & Mean & SD & $95 \% \mathrm{Cl}$ of mean \\
\hline \multicolumn{7}{|l|}{ Joints } \\
\hline Hypertrophy & 26 & 0 & 4 & 0.38 & 1.02 & $(-0.03$ to 0.80$)$ \\
\hline Effusion & 26 & 0 & 16 & 3.85 & 4.14 & (2.17 to 5.52 ) \\
\hline Power Doppler & 26 & 0 & 1 & 0.12 & 0.33 & $(-0.02$ to 0.25$)$ \\
\hline \multicolumn{7}{|l|}{ Entheseal sites } \\
\hline Enthesophyte & 26 & 0 & 2 & 0.15 & 0.54 & $(-0.07$ to 0.37$)$ \\
\hline Calcifications & 26 & 0 & 13 & 4 & 3.44 & (3.15 to 5.93 ) \\
\hline Erosions & 26 & 0 & 2 & 0.50 & 0.86 & (0.15 to 0.85 ) \\
\hline Bursitis & 26 & 0 & 1 & 0.08 & 0.27 & $(-0.03$ to 0.19$)$ \\
\hline Vascularisation & 26 & 0 & 1 & 0.08 & 0.27 & $(-0.03$ to 0.19$)$ \\
\hline
\end{tabular}

was 34.38 months $( \pm 13.89)$ and of TNFi therapy 41.17 months $( \pm 35.97)$. One patient was using low-dose corticosteroid, which was also discontinued at enrolment. On-demand use of NSAIDs was allowed during the study.

Patients showed no signs of active joint disease with TJC (mean \pm SD: $0.19 \pm 0.57$ ) and SJC (mean \pm SD: $0 \pm 0$ ). None of the patients had a DAS28 over 2.6 (mean \pm SD: $1.37 \pm 0.36$; maximum: 2.34). All but one patient (suffering from concomitant muscle dystrophy) also fulfilled the Minimal Disease Activity Criteria for PsA (16). None of the patients had signs of enthesitis with MASES (mean \pm SD: $0 \pm 0$ ) or dactylitis with LDI (mean \pm SD: $0 \pm 0$ ). Patients exhibit virtually no clinical symptoms related to axial joint disease (mean \pm SD BASDAI: 1.55 \pm 1.16 ). Functional status (mean \pm SD HAQ: $0.16 \pm 0.44$ ) and the quality of life of the 26 PsA patients were excellent. Skin disease was virtually absent in the patients (PASI $=0$ in 20 patients; mean \pm SD PASI: $0.22 \pm 0.56$ ) and also nails were normal or showed only minimal involvement (NAPSI $=0$ in 8 patients; mean \pm SD NAPSI: 4.30 \pm 6.90 ).

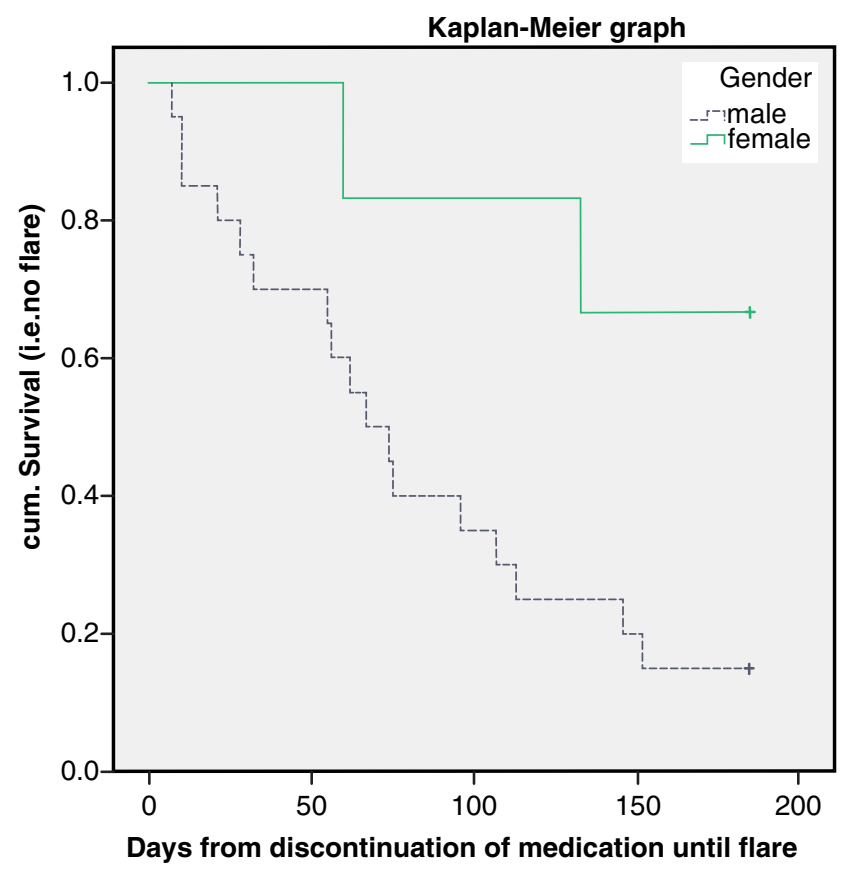

Figure 1 Kaplan-Meier curve showing the loss of sustained remission in relation to time from discontinuation of medications. 


\section{Ultrasound characteristics}

Table 2 shows the ultrasound data of a detailed examination of 30 joints and 20 entheseal sites of the PsA patients at baseline. The most common ultrasonographic findings were the presence of joint effusions (mean \pm SD: $3.85 \pm 4.14$ ) and the presence of calcifications at the entheseal sites (mean \pm SD: 4 \pm 3.44 ). Interestingly, despite the lack of symptoms, three patients showed evidence of synovitis in one joint in the ultrasound examination at baseline. This subclinical synovitis was characterised by the presence of synovial hypertrophy, joint effusion and a positive Doppler signal. Subclinical enthesitis was found in four of the patients.

\section{High frequency of flares after cessation of DMARD therapy in PsA}

After stopping conventional and biologic DMARD therapy in PsA patients, we observed an unexpectedly high incidence of recurrence of disease $(\mathrm{N}=20 ; 76.90 \%)$. Generally, recurrence of symptoms occurred early with a mean $( \pm S D)$ of 74.5 days ( \pm 51.7 days) after discontinuation of treatment. Figure 1 shows a time scale for recurrence of disease in the individual patients. Interestingly, no difference was found among patients treated with MTX and those treated with TNFi for recurrence of disease (MTX: 10 flares/14 patients; TNFi: 10 flares/12 patients).

\section{Parameters predictive for recurrence of disease in PsA}

Inferential statistical results comparing the group of PsA patients who developed recurrence of disease with the ones who maintained remission for at least 6 months are outlined in table 3 . We observed a significant difference with regards to gender and maintenance of drug-free remission, where female patients seemed to be more likely to stay in remission after discontinuation of therapy $(p=0.013)$. In addition, we also observed a tendency for a higher likelihood for recurrence of disease in those

Table 3 Inferential results

\begin{tabular}{|c|c|c|c|c|}
\hline & $\begin{array}{l}\text { Remission } \\
(\mathrm{N}=6)\end{array}$ & $\begin{array}{l}\text { Recurrence } \\
(\mathrm{N}=20)\end{array}$ & Inferential test coefficient & $\mathrm{p}$ Value \\
\hline \multicolumn{5}{|c|}{ Demographic and disease characteristic parameters } \\
\hline Age & $55 \pm 6.39$ & $55.30 \pm 16.28$ & $t(21.75)=-0.07$ & 0.947 \\
\hline Male gender & $2 / 6$ & $18 / 20$ & $x^{2}(1)=8.35$ & 0.013 \\
\hline BMI & $29.60 \pm 5.47$ & $25.57 \pm 2.43$ & $t(5.60)=1.75$ & 0.134 \\
\hline Duration of PsA (years) & $3 \pm 1.41$ & $7.6 \pm 7.33$ & $U=34.50 ; z=-1.57$ & 0.116 \\
\hline Duration of remission (months) & $19.50 \pm 16.74$ & $25.25 \pm 25.62$ & $U=51.50 ; z=-0.521$ & 0.602 \\
\hline Use of anti-TNF- $\alpha$ & $2 / 6$ & $10 / 20$ & $x^{2}(1)=0.52$ & 0.652 \\
\hline Duration of DMARD (months) & $37.83 \pm 12.67$ & $33 \pm 14.52$ & $\mathrm{U}=37.00 ; \mathrm{z}=-0.623$ & 0.533 \\
\hline Duration of TNFi (months) & $37 \pm 1.41$ & $42 \pm 39.70$ & $U=6.50 ; z=-0.753$ & 0.451 \\
\hline TJC & $0.33 \pm 0.82$ & $0.15 \pm 0.49$ & $U=55.50 ; z=-0.49$ & 0.622 \\
\hline SJC & $0.17 \pm 0.41$ & $0.05 \pm 0.22$ & $U=53.00 ; z=-0.922$ & 0.356 \\
\hline VAS patient global $(\mathrm{cm})$ & $0.96 \pm 1.20$ & $0.79 \pm 0.88$ & $U=43.00 ; z=-0.326$ & 0.744 \\
\hline VAS patient pain $(\mathrm{cm})$ & $0.95 \pm 0.68$ & $0.61 \pm 0.79$ & $U=26.50 ; z=-0.850$ & 0.395 \\
\hline VAS physician global (cm) & $0.18 \pm 0.40$ & $0.08 \pm 0.17$ & $\mathrm{U}=48.00 ; z=-0.194$ & 0.846 \\
\hline $\mathrm{CRP}(\mathrm{mg} / \mathrm{dL})$ & $1.82 \pm 2.47$ & $1.74 \pm 1.99$ & $U=49.50 ; z=-0.640$ & 0.522 \\
\hline ESR & $10 \pm 5.66$ & $8.13 \pm 8.46$ & $U=32.00 ; z=-1.185$ & 0.236 \\
\hline \multicolumn{5}{|l|}{ Composite scores } \\
\hline DAS-28 CRP & $1.52 \pm 0.35$ & $1.33 \pm 0.36$ & $\mathrm{U}=30.50 ; z=-1.212$ & 0.225 \\
\hline DAPSA & $2.14 \pm 1.60$ & $1.79 \pm 1.69$ & $U=29.00 ; z=-0.596$ & 0.551 \\
\hline PASDAS & $1.15 \pm 0.624$ & $1.11 \pm 0.83$ & $U=39.00 ; z=-0.447$ & 0.655 \\
\hline HAQ-DI & $0.17 \pm 0.19$ & $0.16 \pm 0.49$ & $U=42.00 ; z=-1.403$ & 0.161 \\
\hline SF-36 (physical component) & $50.16 \pm 5.71$ & $50.74 \pm 9.98$ & $\mathrm{U}=43.00 ; \mathrm{z}=-0.733$ & 0.463 \\
\hline SF-36 (psychological component) & $51.62 \pm 6.74$ & $53.32 \pm 6.40$ & $U=46.00 ; z=-0.533$ & 0.594 \\
\hline FACIT-F & $44.25 \pm 7.80$ & $45.17 \pm 6.71$ & $U=32.00 ; z=-0.342$ & 0.732 \\
\hline BASDAI & $2.12 \pm 1.31$ & $1.39 \pm 1.11$ & $t(5.69)=1.14$ & 0.301 \\
\hline PASI & $0 \pm 0$ & $0.28 \pm 0.63$ & $t(19)=1.99$ & 0.061 \\
\hline NAPSI & $1.83 \pm 2.48$ & $5.05 \pm 7.65$ & $U=43.00 ; z=-1.059$ & 0.289 \\
\hline \multicolumn{5}{|l|}{ US findings joints } \\
\hline Hypertrophy & $0 \pm 0$ & $0.50 \pm 1.15$ & $t(19)=1.95$ & 0.066 \\
\hline Effusion & $3 \pm 2$ & $4.10 \pm 4.61$ & $U=58.00 ; z=-0.123$ & 0.902 \\
\hline Power Doppler & $0.17 \pm 0.41$ & $0.10 \pm 0.31$ & $\mathrm{U}=56.00 ; z=-0.440$ & 0.660 \\
\hline \multicolumn{5}{|l|}{ US findings entheseal sites } \\
\hline Enthesophyte & $0.33 \pm 0.82$ & $0.10 \pm 0.45$ & $U=53.00 ; z=-0.922$ & 0.356 \\
\hline Calcifications & $3 \pm 3.29$ & $5 \pm 3.43$ & $t(24)=-1.26$ & 0.220 \\
\hline Erosions & $0.33 \pm 0.82$ & $0.55 \pm 0.89$ & $U=52.50 ; z=-0.60$ & 0.555 \\
\hline Bursitis & $0.17 \pm 0.41$ & $0.05 \pm 0.22$ & $U=53.00 ; z=-0.922$ & 0.356 \\
\hline Vascularisation & $0 \pm 0$ & $0.10 \pm 0.31$ & $t(19)=1.45$ & 0.163 \\
\hline
\end{tabular}

Indicated are mean \pm SD, except for gender and use of TNFi that indicate the total number of patients.

BASDAI, Bath Ankylosing Spondylitis Disease Activity Index; DAPSA, Disease Activity index for Psoriatic Arthritis; DMARD, disease-modifying antirheumatic drug; ESR, erythrocyte sedimentation rate; PASDAS, Psoriatic Arthritis Disease Activity Score; PASI, Psoriasis Area Severity Index; NAPSI, Nail Psoriasis Severity Index; SJC, Swollen Joint Count; TJC, Tender Joint Count; VAS, visual analogue scale. 
PsA patients with longer disease duration $(p=0.116)$ and more severe skin involvement $(p=0.061)$. The presence of synovial hypertrophy by ultrasound correlated with a higher chance of recurrence of disease $(p=0.066)$. Interestingly, duration of remission did not show any influence on the likelihood for recurrence of disease.

\section{Clinical characteristics of recurrence of disease in PsA patients}

Recurrence of disease was characterised by development of joint pain and/or swelling in all 20 patients (table 4). We did not observe mere worsening of skin disease without recurrence of musculoskeletal symptoms. Recurrence of arthritis was characterised by mean of four painful and two swollen joints. Severity of joint complaints was also reflected by substantial increases of the VAS pain $(4.21 \mathrm{~cm})$ and VAS patient global $(4.19 \mathrm{~cm})$. The great majority $(\mathrm{N}=15 / 20 ; 75 \%)$ of PsA patients also showed a worsening of psoriatic skin disease. Nonetheless, severity of skin disease during recurrence of disease was mild to moderate with a mean PASI score of 1.22. Figure 2 shows a spider web plot graph comparing different domains of disease activity at baseline and during disease recurrence. Clearly, the patient-related outcome measures show the most significant difference. Only few patients developed axial or entheseal symptoms during recurrence of disease (each 15\%). All patients restarted their original type and dosage of DMARD therapy, and remission was regained in all the patients within 3 months.

\section{DISCUSSION}

Due to earlier diagnosis, tighter management and the broader armamentarium of DMARDs, an increasing number of patients with inflammatory arthritis experience sustained clinical remission. ${ }^{18}$ This situation attributes to both RA and PsA patients and represents a future challenge for rheumatologists since patients question the need for ongoing drug therapy despite the absence of musculoskeletal symptoms . High costs of biological DMARD therapy as well as the controversial data on efficacy of MTX in patients of PsA further raise the importance of this question. ${ }^{19}{ }^{20}$ As a matter of fact, two different concepts can be envisioned: (i) long-term successful management of inflammatory disease could lead to a reset of the entire underlying process of immune activation, which allows for cure of disease

\begin{tabular}{|c|c|c|}
\hline Total number of patients & $\mathrm{N}$ & 20 \\
\hline Males & $\mathrm{N}(\%)$ & $18(90 \%)$ \\
\hline Duration of 'drug-free' remission (days) & Mean $\pm S D$ & $74.50 \pm 51.72$ \\
\hline Arthritis* & $\mathrm{N}(\%)$ & $20(100 \%)$ \\
\hline Inflammatory back pain & $\mathrm{N}(\%)$ & $3(15 \%)$ \\
\hline Enthesitis & $\mathrm{N}(\%)$ & $4(20 \%)$ \\
\hline Psoriatic skin disease & $\mathrm{N}(\%)$ & $16(80 \%)$ \\
\hline TJC 68t & Mean \pm SD & $4.05 \pm 5.06$ \\
\hline SJC 66t & Mean \pm SD & $2.53 \pm 3.24$ \\
\hline PASI & Mean $\pm S D$ & $1.22 \pm 1.21$ \\
\hline VAS patient global (cm) & Mean \pm SD & $4.19 \pm 1.81$ \\
\hline VAS patient pain $(\mathrm{cm})$ & Mean \pm SD & $4.21 \pm 1.74$ \\
\hline VAS physician global $(\mathrm{cm}) \dagger$ & Mean \pm SD & $3.79 \pm 1.38$ \\
\hline \multicolumn{3}{|c|}{$\begin{array}{l}\text { *As defined by at least one swollen joint. } \\
\text { †Values assessed in } 19 \text { patients. } \\
\text { ¥Values assessed in } 17 \text { patients. } \\
\text { PASI, Psoriasis Area Severity Index; SJC, Swollen Joint Count; TJC, Tender Joint Count; } \\
\text { VAS, visual analogue scale. }\end{array}$} \\
\hline
\end{tabular}

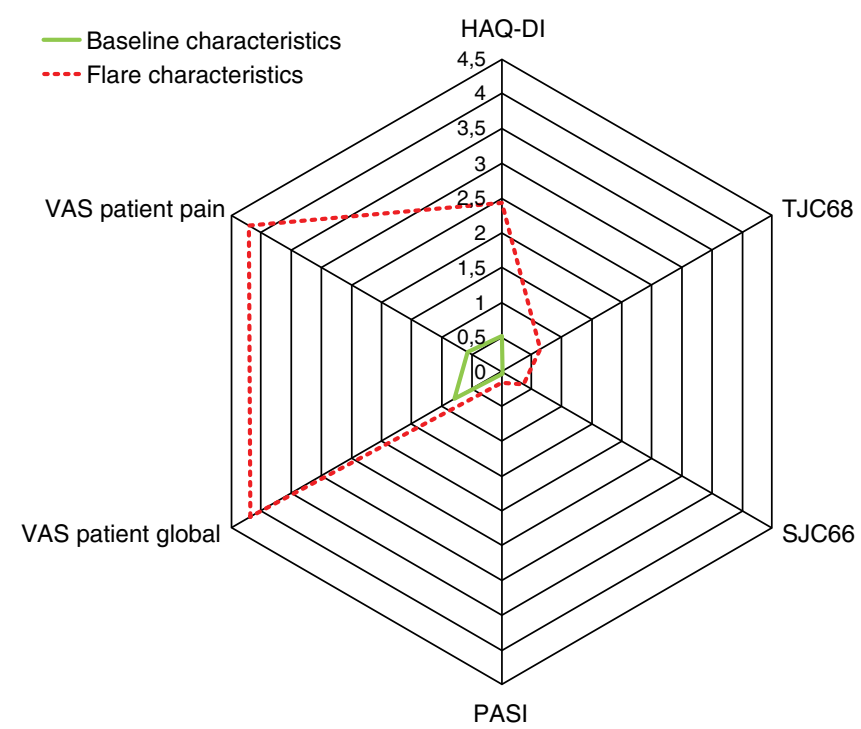

Figure 2 Spider web plot showing the different domains of disease activity in the 20 patients who experienced a flare at baseline and at the time of the flare.

and successful cessation of treatment. In opposition to this view, (ii) current antirheumatic therapy, despite successfully suppressing the inflammatory response, may not cure the underlying cause of disease. This scenario would imply that once treatment has been stopped, disease and, in consequence, also clinical symptoms return.

We were surprised by the extraordinary high rate of recurrence of disease in patients with PSA in continuous remission after stopping treatment. More than two-thirds of the patients had to restart their original medication within the first 6 months of cessation of treatment. One additional patient developed disease activity only 30 days after the 6-month follow-up visit, suggesting that recurrence of PsA can occur even after a 6 months of symptom-free interval. This observation clearly favours the latter of the aforementioned scenarios, suggesting that neither MTX treatment nor TNFi fundamentally change the susceptibility of the patients to develop PsA. The reasons for this situation are unclear, but several explanations may be envisioned: first, genetic susceptibility to develop disturbed barrier function and/or altered immune response with activation of the IL-23/IL-17 axis in the skin may persist lifelong in patients with PsA and cannot be corrected by current antirheumatic interventions. Second, the joints of patients with PsA may be altered and become primed by the inflammatory tissue, possible due to damage of the entheseal organ, the bone and the cartilage. ${ }^{21}$ Affected joints may repeatedly and effectively home inflammatory tissue. This memory function of the tissue is supported by the observation that recurrence of the disease usually occurred at those anatomical sites, which were previously affected by the disease.

The high rate of recurrence of PsA was also unexpected given the strict inclusion criteria we employed in this observational study. Patients had to be without musculoskeletal symptoms, such as joint tenderness, joint swelling, as well as signs of enthesitis or dactylitis for the last 6 months. Also, no change in DMARD medication was allowed during the last 6 months, which excludes inclusion of patients with unstable remission. Furthermore, skin disease was absent or minimal with a mean PASI of less than 0.3 at baseline. Although no formal remission criteria in PsA have been defined to date, the continuous 
absence of musculoskeletal complaints with no or only minimal psoriatic skin disease can considered as ambitious treatment goal in patients with PsA. ${ }^{17}$ Conditions resembling clinical remission of PsA have been reported previously. Their frequency ranges from $18 \%$ to as high as $58 \%$, which is most likely based on the different populations studied, differences in the treatment and the criteria used to define remission. ${ }^{22}{ }^{23}$ It is also important that remission at one point of time in disease does not entirely reflect continuous remission, which needs to be documented during several sequential visits. Recently, Coates and colleagues defined the term minimal disease activity in PsA, ${ }^{17}$ which permits minor residual disease and is intended to define a treatment target for rheumatologists in patients with PsA. The criteria for minimal disease activity in PsA were however not intended to define PsA patients, which are eligible to stop their DMARD medication. Such patients will have to be in true remission without any residual disease activity to justify cessation of treatment.

Our data do not support that discontinuation of DMARD treatment is a feasible option in patients with PsA, even if in remission for more than 6 months. Since the duration of remission did not predict the likelihood of recurrence of disease, we do not have data in support of the concept that the susceptibility to develop PsA changes even in cases of long-term remission. The observation that longer disease duration and synovial hypertrophy by ultrasound are more often associated with the recurrence of PsA suggests that joint damage in conjunction with inflammation may prime these joints for disease and enhance their susceptibility to become affected again. Such concept would further strengthen the importance of early intervention in PsA, which may not only enhance the likelihood of remission of disease as nicely shown by Theander and colleagues $^{5}$ but also raises the perspective to induce drug-free remission and even cure.

Contributors EGA, SF, DAS and KD collected the data. FF, AH, JR and GS designed the study. ME contributed to the data analysis. EGA and GS wrote the manuscript.

Funding This study was supported by the Deutsche Forschungsgemeinschaft (SPP1468-Immunobone), the Bundesministerium für Bildung und Forschung (BMBF; project Ankyloss), the Marie Curie Training Network grant Osteoimmune, the Masterswitch and Euroteam project of the European Union and the IMI-funded project BTCure.

Competing interests None.

Ethics approval Ethics approval was obtained from the Local Ethics Committee.

Provenance and peer review Not commissioned; externally peer reviewed.

\section{REFERENCES}

1 Veale DJ. New therapies and new goals for psoriatic arthritis. Arthritis Rheum 2011:63:874-6.

2 Kane D, Stafford L, Bresnihan B, et al. A prospective, clinical and radiological study of early psoriatic arthritis: an early synovitis clinic experience. Rheumatology (Oxford) 2003;42:1460-8
3 Gladman DD, Thavaneswaran A, Chandran V, et al. Do patients with psoriatic arthritis who present early fare better than those presenting later in the disease? Ann Rheum Dis 2011;70:2152-4.

4 Queiro-Silva R, Torre-Alonso JC, Tinture-Eguren T, et al. A polyarticular onset predicts erosive and deforming disease in psoriatic arthritis. Ann Rheum Dis 2003;62:68-70.

5 Theander E, Husmark T, Alenius GM, et al. Early psoriatic arthritis: short symptom duration, male gender and preserved physical functioning at presentation predict favourable outcome at 5-year follow-up. Results from the Swedish Early Psoriatic Arthritis Register (SwePsA). Ann Rheum Dis 2014;73:407-13.

6 Baranauskaite A, Raffayova H, Kungurov NV, et al. Infliximab plus methotrexate is superior to methotrexate alone in the treatment of psoriatic arthritis in methotrexate-naive patients: the RESPOND study. Ann Rheum Dis 2012;71:541-8.

7 Ritchlin CT, Kavanaugh A, Gladman DD, et al. Treatment recommendations for psoriatic arthritis. Ann Rheum Dis 2009;68:1387-94.

8 Kingsley GH, Kowalczyk A, Taylor $\mathrm{H}$, et al. A randomized placebo-controlled trial of methotrexate in psoriatic arthritis. Rheumatology (Oxford) 2012;51:1368-77.

9 Nash P, Clegg DO. Psoriatic arthritis therapy: NSAIDs and traditional DMARDs. Ann Rheum Dis 2005;64(Suppl 2):ii74-7.

10 Caperon A, Helliwell PS. Remission in psoriatic arthritis. J Rheumatol Supp/ 2012;89:19-21.

11 Coates LC, Mumtaz A, Helliwell PS, et al. Development of a disease severity and responder index for psoriatic arthritis (PSA)--report of the OMERACT 10 PSA special interest group. J Rheumatol 2011;38:1496-501.

12 Kavanaugh A, Fransen J. Defining remission in psoriatic arthritis. Clin Exp Rheumatol 2006;24:S-83-7.

13 Mease PJ. Measures of psoriatic arthritis: Tender and Swollen Joint Assessment, Psoriasis Area and Severity Index (PASI), Nail Psoriasis Severity Index (NAPSI), Modified Nail Psoriasis Severity Index (mNAPSI), Mander/Newcastle Enthesitis Index (MEI), Leeds Enthesitis Index (LEI), Spondyloarthritis Research Consortium of Canada (SPARCC), Maastricht Ankylosing Spondylitis Enthesis Score (MASES), Leeds Dactylitis Index (LDI), Patient Global for Psoriatic Arthritis, Dermatology Life Quality Index (DLQI), Psoriatic Arthritis Quality of Life (PsAQOL), Functional Assessment of Chronic Illness Therapy-Fatigue (FACIT-F), Psoriatic Arthritis Response Criteria (PsARC), Psoriatic Arthritis Joint Activity Index (PsAJAI), Disease Activity in Psoriatic Arthritis (DAPSA), and Composite Psoriatic Disease Activity Index (CPDAI). Arthritis Care Res (Hoboken) 2011;63(Suppl 11):S64-85.

14 Palominos PE, Gaujoux-Viala C, Fautrel B, et al. Clinical outcomes in psoriatic arthritis: a systematic literature review. Arthritis Care Res (Hoboken) 2012;64:397-406.

15 Schoels M, Aletaha D, Funovits J, et al. Application of the DAREA/DAPSA score for assessment of disease activity in psoriatic arthritis. Ann Rheum Dis 2010;69:1441-7.

16 Helliwell PS, FitzGerald O, Fransen J, et al. The development of candidate composite disease activity and responder indices for psoriatic arthritis (GRACE project). Ann Rheum Dis 2013;72:986-91.

17 Coates LC, Fransen J, Helliwell PS. Defining minimal disease activity in psoriatic arthritis: a proposed objective target for treatment. Ann Rheum Dis 2010;69:48-53.

18 Saber TP, $\mathrm{Ng} \mathrm{CT}$, Renard G, et al. Remission in psoriatic arthritis: is it possible and how can it be predicted? Arthritis Res Ther 2010;12:R94.

19 Cantini F, Niccoli L, Cassara E, et al. Sustained maintenance of clinical remission after adalimumab dose reduction in patients with early psoriatic arthritis: a long-term follow-up study. Biologics 2012;6:201-6.

20 Olivieri I, D'Angelo S, Padula A, et al. Can we reduce the dosage of biologics in spondyloarthritis? Autoimmun Rev 2013;12:691-3.

21 Ritchlin CT, Haas-Smith SA, Li P, et al. Mechanisms of TNF-alpha- and RANKL-mediated osteoclastogenesis and bone resorption in psoriatic arthritis. J Clin Invest 2003;111:821-31.

22 Cantini F, Niccoli L, Nannini C, et al. Criteria, frequency, and duration of clinical remission in psoriatic arthritis patients with peripheral involvement requiring second-line drugs. J Rheumatol Supp/ 2009;83:78-80.

23 Gladman DD, Hing EN, Schentag CT, et al. Remission in psoriatic arthritis. J Rheumatol 2001;28:1045-8. 
ARD High incidence of disease recurrence after discontinuation of disease-modifying antirheumatic drug treatment in patients with psoriatic arthritis in remission

Elizabeth G Araujo, Stephanie Finzel, Matthias Englbrecht, Dominik A Schreiber, Francesca Faustini, Axel Hueber, Kemal Nas, Juergen Rech and Georg Schett

Ann Rheum Dis 2015 74: 655-660 originally published online December 12, 2013

doi: 10.1136/annrheumdis-2013-204229

Updated information and services can be found at:

http://ard.bmj.com/content/74/4/655

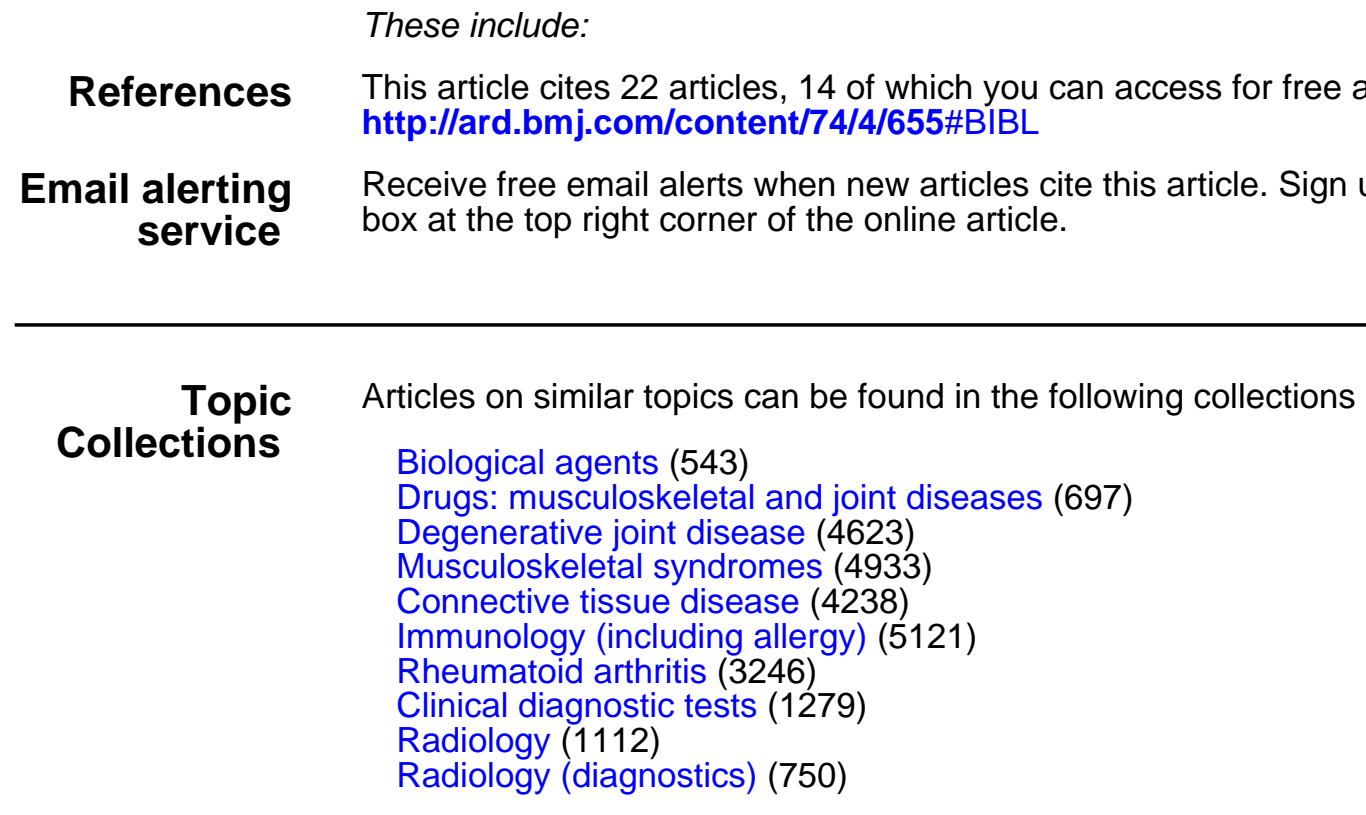

Notes

To request permissions go to:

http://group.bmj.com/group/rights-licensing/permissions

To order reprints go to:

http://journals.bmj.com/cgi/reprintform

To subscribe to BMJ go to:

http://group.bmj.com/subscribe/ 